\title{
Behcet's syndrome in 32 patients in Yorkshire
}

\author{
M. ANNE CHAMBERLAIN \\ From the General Infirmary at Leeds
}

SUMMARY Thirty-two patients with Behcet's syndrome were surveyed clinically, radiologically, and immunologically. HLA antigens were determined in a proportion. The patients were culled from a defined geographical area (Yorkshire) with a population of 5 million. 21 patients satisfied Mason and Barnes's (1969) criteria for major disease. $100 \%$ had mouth ulceration, $91 \%$ genital ulceration, $66 \%$ skin complaints, and $63 \%$ arthritis (of the nonerosive type previously documented). 3 patients had gastrointestinal involvement, one of whom had proven Crohn's disease. One patient had psoriasis. One patient had a popliteal artery aneurysm resected and one has since had surgery after the development of a tracheo-oesophageal fistula. No sacroilititis was found.

Behcet's syndrome is an uncommon disorder first described by Professor Behcet in 1937 but with a long pedigree possibly going back to Hippocrates. There is a substantial ophthalmological and dermatological literature dating from the turn of the century, the two streams converging over the past 20 years. Information has accumulated at an increasing rate over the last few years and has included several large series and reviews (Chajek and Fainaru, 1975; Zizic and Stevens 1975). Classically Behcet's syndrome is considered to consist of a triad of findings (oral and genital ulceration and iritis) but many authors have widened the scope of the diagnosis and varied the diagnostic criteria. Curth (1946) suggested that the diagnosis could be made when two features of the triad were present. The many names for different groups of features found in Behcet's syndrome have led to confusion in diagnosis. Dowling (1961) commented on the difficulties of establishing a certain diagnosis. Recently in an attempt to clarify the position, Mason and Barnes (1969) suggested a series of major and minor criteria.

Originally the disease appeared largely confined to the Middle East but recently reports have come from all parts of the world, particularly from Japan. One of the few epidemiological reports suggests that the disease occurs in 1 in 10000 of the population of Hokkaido, a remote part of Japan (Aoki et al., 1971).

Work done in the unit at Leeds over the past 10 years has led to the concept of the seronegative

Accepted for publication May 9, 1977

Correspondence to Dr. M. A. Chamberlain, Rheumatology and Rehabilitation, University of Leeds Medical School, 36 Clarendon Road, Leeds LS2 9PJ spond-arthropathies. Behcet's syndrome has been tentatively placed within this orbit as there are certain features of the disorder which are also found in ulcerative colitis and ankylosing spondylitis (for example, erythema nodosum, mouth ulceration, and iridocyclitis). It may be that these features all arise on the basis of a common genetic background. Studies of histocompatibility (HLA) antigens offer one means of looking at this in more detail. The incidence of HLA B27 is raised in ankylosing spondylitis, as it is in patients with uveitis from other causes.

The work reported here is part of a family study of Behcet's syndrome in the county of Yorkshire. Analysis of probands aimed to define the major components of the disorder as presenting in a defined geographical area and to determine the frequency of the disease in that area, as well as the prevalence of sacroiliitis and the various HLA antigens. The presence of coincident diseases associated with seronegative arthropathies has been noted in an attempt to learn more about the nature of Behcet's syndrome and its relation to the seronegative arthropathies.

\section{Patients}

\section{SOURCE}

All general practitioners in Yorkshire were contacted via the appropriate executive councils for the names of patients with a possible diagnosis of Behcet's syndrome and for permission to approach them. Hospital colleagues in the region were also contacted. A standard letter was sent to each of those named inviting them to participate in the survey. 
Those willing were questioned and examined if they satisfied the following criteria. (1) Currently resident in the County of Yorkshire. (2) Mouth ulceration had been recurrent over at least a 6-month period. (3) Another feature of the disease was present.

\section{EXAMINATION}

The method used was substantially that outlined by Moll (1971) with a questionnaire adapted for Behcet's syndrome. A standard proforma was designed to give details of the various manifestations of the disease. Thus, skin complaints such as psoriasis, acne, erythema nodosum, and infective lesions were sought. Detailed features of mouth and genital ulceration were noted and patients with Reiter's disease excluded. Conjunctivitis, iritis, backache, sacroiliitis, arthritis, thrombosis, and neurological abnormalities were all recorded.

A full clinical examination was supplemented by measurement of chest expansion and lumbar spinal movement, as described by Moll et al. (1972) and Moll and Wright (1972). Blood was taken for an immunological profile, haemoglobin, erythrocyte sedimentation rate, and white cell count. HLA antigen profiles were also undertaken on a substantial number of patients by Dr. S. M. Rajah of the Leeds Blood Transfusion Unit. Radiographs of the sacroiliac joints were obtained from males over the age of 15 years and females over the age of 45 years, according to MRC criteria and using a $4^{\prime \prime}$ gonad protector. The hands, feet, and any affected joints were $x$-rayed.

\section{Methods}

\section{IMMUNOFLUORESCENCE STUDIES}

\section{Detection of autoantibodies}

Antigens were provided by unfixed cryostat sections of human kidney, stomach, and thyroid, mounted as one block, and by sections of guinea pig lip and oesophagus mounted as a second block. Sera were reacted with human tissues at an initial dilution of $1: 4$ and with guinea pig tissues at an initial dilution of $1: 15$, using standard indirect immunofluorescent tests. For these tests multivalent antihuman immunoglobulin antisera labelled with fluorescein isothiocyanate were used at dilutions of 1:64. Sections were examined under incident illumination on a Leitz Orthoplan microscope, using narrow band excitation $(495 \mathrm{~mm}$ ) and a K530 barrier filter.

\section{Immunoglobulins}

IgG, IgM, and IgA were analysed quantitatively and the values obtained recorded in a graded fashion for computer analysis as follows:

\begin{tabular}{|c|c|c|c|}
\hline & $\operatorname{Ig} G(g / l)$ & $\operatorname{IgM}(g / l)$ & $\operatorname{IgA}(g / l)$ \\
\hline $\begin{array}{l}0 \text { unknown } \\
1 \text { below normal } \\
2 \text { normal range } \\
3 \text { slightly raised } \\
4 \text { greatly raised }\end{array}$ & $\begin{aligned} &< 9 \cdot 8 \\
& 9 \cdot 8-15 \cdot 2 \\
& 15 \cdot 2-20 \cdot 1 \\
&>20 \cdot 1\end{aligned}$ & $\begin{aligned} & \\
<0 & \cdot 51 \\
& 0 \cdot 51-1 \cdot 09 \\
& 1 \cdot 10-2 \cdot 0 \\
> & 2 \cdot 0\end{aligned}$ & $\begin{aligned} &- \\
&<1 \cdot 67 \\
& 1 \cdot 67-3 \cdot 09 \\
& 3 \cdot 10-3 \cdot 50 \\
&>3 \cdot 50\end{aligned}$ \\
\hline
\end{tabular}

Data were analysed conventionally by calculatiof the percentage incidence of various characteristics: Data were also prepared for Q-analysis (Atkin 1974) as described fully elsewhere (Chamberlain, 197\% Q-analysis provides a method of studying the cos nectivities between members of a set $Y$ when the are related (via a mathematical relation) to anothigy set $X$, in this case: $Y=$ (names of individuad people), $X=$ (names of disease attributes).

Q-analysis is a dynamic and flexible process, one of its merits being that no initial assumptions hame to be made as to which features in a large mass of data are associated individually or in subgroups. A consistent coding principle was adopted for the computer analysis: absence of data was indicatęd by 0 , normal values were presented by unity, and increasing pathology indicated by progressigety higher digits. This allowed study of the connegion between disease attributes at increasing levefi of diagnostic certainty.

In addition the patients could also be stratified in several established ways in this survey. 3 patienats showed the classical triad of features. Using Masofn and Barnes's (1969) criteria (but excluding the family history, as the value of this was under investigation; and cardiovascular disease, as nुo details of this were available), 21 patients satisfigd the criteria for definite disease. Radiographs of the sacroiliac joints were graded as described by Macrige et al. (1971).

\section{Results}

Forty-one subjects were contacted, 33 agreed to tade part in the survey; 1 of these was rejected as nt satisfying the entry criteria and thus the number with Behcet's disease entering the survey was (Table 1). (17 were referred from general practitioneps and 15 from hospitals.) The group was composediof 20 females and 12 males in whom the mean age off onset was 24.7 years, only 4 patients developing the disorder after the age of $\mathbf{4 0}$ years (Table 2). Moutth ulceration was present in all cases, by definition, being the presenting feature in 25 patients; in 16 isit preceded all other symptoms. Arthritis was the earliest feature in 3 , skin complaints in 10, a gegd genital ulceration in 2 (Table 3 ). The major cliniçal features of the disorder are shown in Table 4 , तु 
Table 132 patients diagnosed as having Behcet's syndrome

\begin{tabular}{|c|c|c|c|c|c|c|c|c|c|c|c|c|}
\hline \multirow[b]{2}{*}{$\begin{array}{l}\text { Case } \\
\text { no. }\end{array}$} & \multirow[b]{2}{*}{$M / F$} & \multicolumn{11}{|c|}{ Laboratory findings } \\
\hline & & $M U$ & $G \boldsymbol{U}$ & Iritis & Skin lesions* & $G I$ & Vasculart & $\begin{array}{l}\text { Arth- } \\
\text { ritis }\end{array}$ & CNS & $S C A T$ & $H L A B 27$ & Comments \\
\hline 30 & $\mathbf{M}$ & + & + & + & $\mathbf{A}, \mathbf{P}$ & & $\mathbf{T}$ & + & + & 0 & 0 & $\mathbf{R}$ macular haemorrhage \\
\hline 31 & $\mathbf{M}$ & + & + & + & A, & & & + & + & 0 & + & \\
\hline 32 & $\mathbf{M}$ & + & + & + & $\mathrm{E}$ & & $\mathrm{Ar}$ & + & & 0 & 0 & $\mathbf{R}$ popliteal artery aneurysm \\
\hline \multicolumn{13}{|c|}{ Patients with definite Behcet's syndrome (Mason \& Barnes, 1969) } \\
\hline 1 & $\mathbf{F}$ & + & + & $\mathbf{C}$ & $\mathbf{A}$ & & $\mathbf{T}$ & + & + & 0 & 0 & \\
\hline 2 & $\mathbf{F}$ & + & + & & & + & & + & & 0 & NT & Rectal and anal ulcers \\
\hline 3 & $\mathbf{M}$ & + & + & $\mathrm{C}$ & A, S, E, M & & & + & & 0 & 0 & \\
\hline 5 & $\mathbf{F}$ & + & + & & $\mathbf{P}$ & & & & & 0 & 0 & Arytenoid ulcer \\
\hline 6 & $\mathbf{M}$ & + & + & & $\mathbf{A}, \mathbf{S}$ & & & + & + & 0 & NT & \\
\hline 8 & $\mathbf{F}$ & + & + & & $\mathrm{E}$ & & & + & + & 0 & 0 & \\
\hline 9 & $\mathbf{M}$ & + & + & & $\mathbf{A}, \mathbf{S}, \mathbf{E}, \mathbf{P}$ & & $\mathbf{T}$ & & & 0 & 0 & \\
\hline 10 & $\mathbf{M}$ & + & + & & $\mathbf{S}$ & & $\mathbf{T}$ & + & & 0 & 0 & Tracheo-oesophageal fistula \\
\hline 12 & $\mathbf{M}$ & + & + & & A, S, Ps, E & & & + & & 0 & NT & Psoriasis, died \\
\hline 14 & $\mathbf{F}$ & + & + & & $\mathbf{A}, \mathbf{S}$ & & $\mathrm{T}$ & & & 0 & 0 & \\
\hline 15 & $\mathbf{M}$ & + & + & & $\mathbf{S}, \mathbf{E}$ & & $\mathbf{T}$ & + & & 0 & NT & $\begin{array}{l}\text { Round cell infiltrate in } \\
\text { thickened vascular end- } \\
\text { othelium of arterioles }\end{array}$ \\
\hline 17 & $\mathbf{F}$ & + & + & & $\mathbf{P}$ & + & & & & 0 & NT & $\begin{array}{l}\text { Nonspecific caecal ulcera- } \\
\text { tion }\end{array}$ \\
\hline 22 & $\mathbf{F}$ & + & + & & $\mathbf{E}$ & + & & + & + & 0 & NT & Crohn's disease \\
\hline 23 & $\mathbf{F}$ & + & + & & $\mathbf{A}$ & & & & & 0 & 0 & \\
\hline 25 & $\mathbf{F}$ & + & + & & $\mathbf{U}$ & & & $\mathbf{R A}$ & & + & + & $\begin{array}{l}\text { Anal and buttock ulcers; } \\
\text { nodular RA }\end{array}$ \\
\hline 26 & $\mathbf{M}$ & + & + & & $\mathbf{S}$ & & & + & & 0 & 0 & Aged 8 \\
\hline 28 & $\mathbf{F}$ & + & + & & $\mathbf{S}, \mathbf{M}$ & & & & & 0 & 0 & \\
\hline 29 & $\mathbf{F}$ & + & + & & $\mathbf{S}, \mathbf{E}, \mathbf{M}, \mathbf{P}$ & & & + & ++ & NT & NT & Died quadriplegic \\
\hline \multicolumn{13}{|c|}{ Patients with possible Behcet's syndrome } \\
\hline 4 & $\mathbf{F}$ & + & + & C & & & & OA & & 0 & + & \\
\hline 7 & $\mathrm{~F}$ & + & + & & & & & OA & + & $\mathbf{0}$ & NT & \\
\hline 11 & $\mathbf{F}$ & + & + & & & & & + & & 0 & + & \\
\hline 16 & $\mathbf{F}$ & + & + & & & & & & & 0 & NT & \\
\hline 18 & $\mathbf{F}$ & + & + & & & & & & & $\mathbf{0}$ & 0 & \\
\hline 19 & $\mathbf{M}$ & + & 0 & C & $\mathbf{A}, \mathbf{S}$ & & & & & 0 & 0 & Aged 11 \\
\hline 20 & $\mathbf{F}$ & + & + & & & & & & & 0 & 0 & Aged 15 \\
\hline 21 & $\mathbf{F}$ & + & + & & & & & & & 0 & 0 & \\
\hline 24 & $\mathbf{F}$ & + & 0 & & & & $\mathbf{T}$ & & & 0 & + & Recurrent vaginitis \\
\hline 27 & $\mathbf{F}$ & + & + & & & & & RA & & 0 & 0 & \\
\hline 33 & $\mathbf{M}$ & + & 0 & + & & & & RA & & 0 & + & \\
\hline Total & & 32 & 29 & 4 & 21 & 3 & 8 & 20 & 8 & 1 & 6 & \\
\hline
\end{tabular}

MU, GU = mouth and genital ulcers; $\mathbf{C}=$ conjunctivitis (recurrent); $\mathbf{G I}=$ gastrointestinal; SCAT $=$ sheep cell agglutination test; $+=$ positive; $\mathrm{NT}=$ not tested.

${ }^{*} \mathbf{A}=$ acne; $\mathbf{S}=$ sepsis; Ps $=$ psoriasis; $\mathbf{E}=$ erythema nodosum; $\mathbf{M}=$ maculopapular rash; $\mathbf{P}=$ sepsis on pin prick (recurrent); $\mathbf{U}=$ ulcers on skin.

$\dagger \mathrm{T}=$ thrombophlebitis; $\mathrm{Ar}=$ arterial lesions.

$\ddagger+=$ nondestructive arthritis; $\mathbf{O A}=$ arthritis with $x$-ray evidence of osteoarthrosis; $\mathbf{R A}=$ clinical rheunatoid arthritis.

Case 13 did not satisfy every criteria (see text).

Table 2 Behcet's syndrome in 32 patients in Yorkshire: onset of disease by decade

\begin{tabular}{ll}
\hline Years & No. of patients \\
\hline $0-10$ & 8 \\
$11-20$ & 8 \\
$21-30$ & 5 \\
$31-40$ & 7 \\
$41-50$ & 1 \\
$51-60$ & 2 \\
$61+$ & 1 \\
\hline
\end{tabular}

which it will be seen that genital ulceration and arthritis were dominant.

One patient had psoriasis, 1 suffered from Crohn's disease leading to colectomy, 1 complained of perianal ulceration, and a further patient had a caecectomy for nonspecific caecal ulceration. 2
Table 3 Onset of Behcet's syndrome: presenting features

\begin{tabular}{lc}
\hline Eye complaints alone & 1 \\
Genital ulceration alone (GU) & 2 \\
Arthritis alone & 3 \\
Mouth ulceration tother features & $9(\mathrm{MU}+\mathrm{GU}=6)$ \\
Skin complaints alone & 10 \\
Mouth ulceration only & 16 \\
\hline
\end{tabular}

patients died during the survey. One, a patient with late-onset Behcet's disease who was treated for this and for severe psoriasis with high dosages of corticosteroids, died of Gram-negative septicaemia. The other had been quadriplegic and dysarthric due to long-standing Behcet's disease and died of uraemia and large necrotic bedsores during the survey. 
Table 4 Characteristics of patients with Behcet's syndrome in Yorkshire

\begin{tabular}{lcccr}
\hline & $\begin{array}{l}M \\
(n=12)\end{array}$ & $\begin{array}{l}F \\
(n=20)\end{array}$ & $\begin{array}{l}\text { Total } \\
(n=32)\end{array}$ & $\%$ \\
\hline Gastrointestinal disorder & 0 & 3 & 3 & 9 \\
Vasculitis & 4 & 4 & 8 & 25 \\
Neurological complaints & 3 & 5 & 8 & 25 \\
Eye complaints (all) & 5 & 3 & 8 & 25 \\
Skin complaints (all) & 11 & 10 & 21 & 66 \\
Arthritis & 10 & 10 & 20 & 63 \\
Genital ulcers & 10 & 19 & 29 & 91 \\
Mouth ulcers & 12 & 20 & 32 & 100 \\
\hline
\end{tabular}

\section{MOUTH ULCERATION}

Many authors have commented that mouth ulceration in Behcet's syndrome has no specific features and that the individual ulcers may be aphthous or herpetiform. This is undoubtedly true when the syndrome is mild but when florid the picture is dramatic and even diagnostic, ulcers extending from the lips to the fauces and into the oesophagus where they cause substernal pain and difficulty in swallowing. At this stage ulcers are usually numerous, large, deep, and may even result in scarring. One patient had surgery to relieve subsequent circum-oral contractures. Another was found to have an arytenoid ulcer and one male in our series has recently developed a tracheo-oesophageal fistula, secondary to Behcet's ulceration. Frequently the ulcers are so painful that the patients only eat liquid foods, after the application of local anaesthetic. Ulcers may be present almost continuously with only short intervals between attacks and with little periodicity in relation to other features of the disorder or to the menses. On the other hand, they are often infrequent, small, and scanty.

Various medications were tried by all patients and indeed were so numerous and varied that no statistical analysis of their effect has been attempted.

\section{GENITAL ULCERATION}

Genital ulceration was present in almost all patients (10 male, 19 female) often beginning shortly after mouth ulceration. Either the mucosa or the skin of the area was affected. Vaginal or cervical ulceration was frequently detectable only by presence of a vaginal discharge, bleeding, or dyspareunia, the ulcerated area often being painless although tender on contact; vulval ulceration occasionally led to labial scarring and destruction.

Discussion showed that the possibility of the disease being venereal had often been an unresolved source of anxiety for the proband and/or their spouse. Indeed, 10 patients with genital ulceration had experienced depression, made suicidal bids, or had suffered marriage breakdown.

\section{SKIN ABNORMALITIES AND SEPSIS}

(TABLE 5)

It was our impression that sepsis was frequent but usually minor in these patients. Acne was present ino 10 (and conjunctivitis and styes were commonly? reported). Erythema nodosum had occurred at some stage in the disorder in 8 , and other conditions such $\frac{\bar{\rho}}{\vec{D}}$ as maculopapular rashes were noted in 3 (Table 7). $\triangle$ One patient had psoriasis. The development of pustular lesions at the site of needle puncture hadbeen commented on by Blobner (1937) and others. and were thought to be diagnostic of the condition. $\vec{\omega}$ A history of such lesions was given by 5 of our patients and was never recorded from spouses or relatives. The relationship of sepsis to the syndromein has been commented on by Behcet himself but has never been clear.

ARTHRITIS (TABLE 6)

Twenty patients in this series suffered from someform of arthritis (the mean age of onset being some 2 years after the beginning of the disease itself mean 27.4 years, range 5-64 years). Of 15 patients judged to have Behcet's arthritis, 3 experiencedp arthralgia and 12 had documented synovitis whighwas often spasmodic but not truly migratory aso left no sequelae, either radiological or clinical.

Table 5 Behcet's syndrome: skin conditions

\begin{tabular}{llll}
\hline & $\begin{array}{l}\text { Total } \\
(n=32)\end{array}$ & $\begin{array}{l}M \\
(n=12)\end{array}$ & $\begin{array}{l}F \\
(n=20)\end{array}$ \\
\hline Acne & 10 & 7 & 3 \\
Psoriasis & 1 & 1 & 0 \\
Erythema nodosum & 8 & 5 & 3 \\
Maculopapular rash & 3 & 1 & 2 \\
\hline
\end{tabular}

Table 615 patients with nonerosive arthritis of Behcet's syndrome

\begin{tabular}{|c|c|c|}
\hline Joint & $\begin{array}{l}\text { Presenting joint } \\
\text { (no. of patients) }\end{array}$ & $\begin{array}{l}\text { Dominant affected joint } \\
\text { (no. of patients) }\end{array}$ \\
\hline Shoulder & 3 & 3 \\
\hline Elbow & 1 & 0 \\
\hline Wrist & 2 & 1 \\
\hline $\begin{array}{l}\text { Metacarpo- } \\
\text { phalangeal }\end{array}$ & 0 & 0 \\
\hline $\begin{array}{l}\text { Proximal inter- } \\
\text { phalangeal }\end{array}$ & 2 & 1 \\
\hline $\begin{array}{l}\text { Total upper } \\
\text { limb joints }\end{array}$ & 8 & 5 \\
\hline Hip & 1 & 0 \\
\hline Knee & 3 & 6 \\
\hline Ankle & 2 & 3 \\
\hline $\begin{array}{l}\text { Metatarso- } \\
\text { phalangeal }\end{array}$ & $\mathbf{0}$ & 0 \\
\hline Interphalangeal & 1 & 1 \\
\hline $\begin{array}{l}\text { Total lower } \\
\text { limb joints }\end{array}$ & 7 & 10 \\
\hline
\end{tabular}


these 15, the shoulder and knee joints were first affected and large joints were affected more commonly than small joints (Table 6). 2 patients suffered a nonarthritis of the knee. None had ankylosing spondylitis or gout. The patient with psoriasis (Case 12) had radiological evidence only of osteoarthrosis of the toes and clinically a palindromic polyarthritis of the knees, elbows, and toes which was thought to be due to Behcet's syndrome, since it was coincident with other features of Behcet's disease.

Of the 5 further patients, 3 had clinical rheumatoid arthritis substantiated in 2 cases by nodules and subluxed joints and in 1 by seropositivity ( $x$-rays unavailable), and the remaining 2 cases had clinical and radiological evidence of osteoarthrosis.

\section{BACKACHE (TABLE 7)}

Eleven patients complained of lumbar pain at some stage, 3 also experiencing pain in thoracic or cervical regions. The mean age of onset of pain was 35 years (range 19-35 years). In all but 2 pain had been short-lived ( 2 weeks or less) and appeared to contribute little to the suffering experienced by patients in the course of Behcet's disorder, even though sciatica accompanied lumbar pain in 60 . 2 of the 3 patients with low back pain and reduced lumbar movement, according to Moll's criteria, had normal radiographs of the SI joints. The third was not $x$-rayed.

\section{EYE IN VOLVEMENT}

Recurrent conjunctivitis was found in 4 patients and was of little importance. In contrast, where iridocyclitis had occurred (4 males) it was severe, chronic, and a prominent feature of the disease which was difficult to bring under control.

\section{NEUROLOGY}

While a quarter of the patients admitted on direct questioning to having had paraesthesiae and numbness, no abnormalities were detected clinically at the time of interview except in one patient (Case 29) who had significant neurological involvement and died at the age of 40 years of uraemia (see above)

\section{VASCULAR INVOLVEMENT}

Eight patients (4 male, 4 female) had vascular abnormalities. 7 had experienced thrombophlebitis

Table 7 Behcet's syndrome: chest expansion and spinal movements in probands

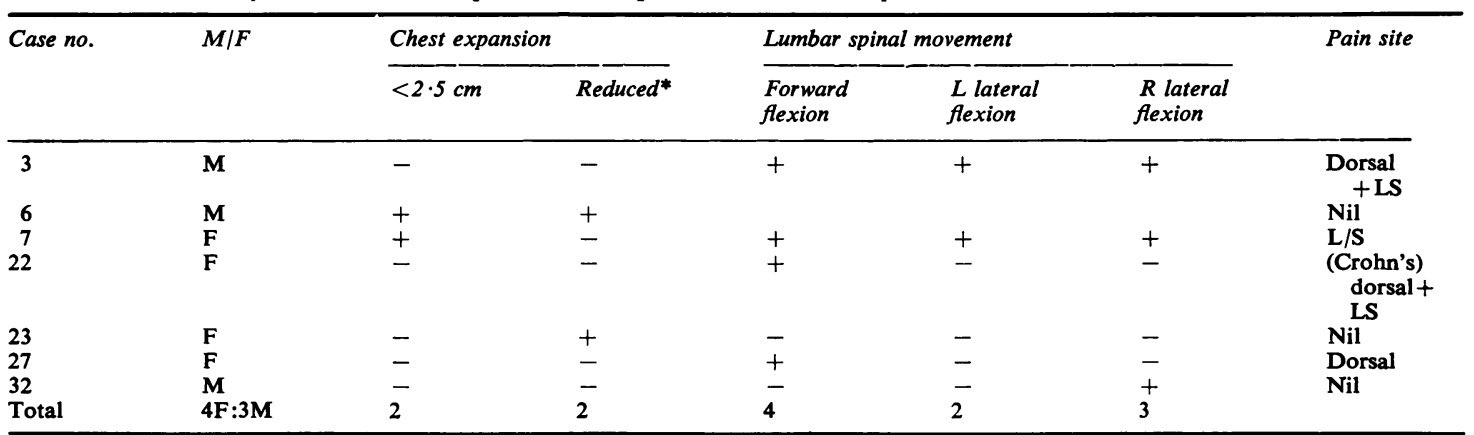

*J. Moll's criteria.

Table 8 Phlebitis (7) and arteritis (I) in Behcet's syndrome (32 patients): characteristics of patients with vascular involvement

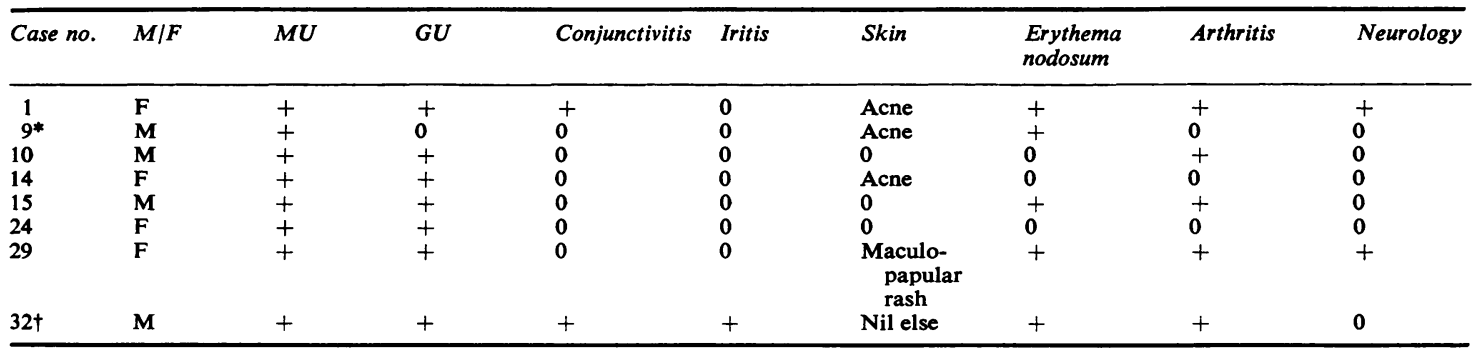

*Inferior vena caval thrombosis also.

+ Resected aneurysm of popliteal artery.

MU and $G U=$ mouth and genital ulceration. 
of the deep veins of the legs extending in one man to the inferior vena cava. The eighth patient, also a young man, had undergone a successful resection of a popliteal artery aneurysm. It was not possible to relate this complaint to the other features of the disease or to the severity of the disorder (Table 8).

\section{GASTROINTESTINAL INVOLVEMENT}

This occurred in 3 cases. (1) One young woman had Crohn's disease proven on resection (Case 22). History. A small Pakistani woman of approximately 33 years of age, resident in England for 5 years. She had had mouth and genital ulcers since the age of 30 , and 3 years before these symptoms (i.e. in 1966) had complained of erythema nodosum and a polyarthritis of the elbows, left wrist, both shoulders, and knees. $X$-rays had shown no bony lesions. Chest $x$-ray was clear. In 1968 she was reported to have had an eosinophilia of $13 \%$; in 1969 she underwent resection of the small intestine for diarrhoea, the barium meal and follow-through having been reported as normal. Pathology report stated, 'A loop of small intestine $25 \mathrm{~cm}$ long with a thickened mucosa and wall about the middle. On either side the bowel looks normal. The thickened lesion shows shallow ulcers. Mesentery at this part is hard. Histology shows that the mesentery contains bowel contents and contains a dense, acute, neutrophil infiltrate. Perforation. The bowel shows epitheloid granulomatous lesions with giant cells and transmural infiltrate in places. No tubercle bacilli seen by special stain. The findings are consistent with Crohn's disease.'

After resection joint symptoms worsened. She did not complain of back pain at any time; there was a negative history of sepsis on skin puncture and no other relevant history. Examination showed a single deep slit-like mouth ulcer, absent right labium majorum without scarring or ulceration, reduced forward flexion of the lumbar spine, minimal limitation of elbow extension, tenderness of both sternoclavicular joints, and a flexor tensosynovitis of the left middle finger. Latex and sheep cell agglutination tests for rheumatoid factor were negative, immunoglobulins were high: IgG 17.0 $\mathrm{g} / 1, \operatorname{IgA} 4 \cdot 1 \mathrm{~g} / 1, \operatorname{IgM} 2 \cdot 1 \mathrm{~g} / \mathrm{l}$. No $x$-rays of the sacroiliac joints were taken because of the patient's age. HLA antigens were not determined.

(2) A second patient (Case 17) had a resection of the caecum for a nonspecific caecal ulcer. History. A 33-year-old married woman had had frequent mouth ulcers since the birth of her first child when she was 21 . Genital ulceration began at the age of 26 years and there had been much marital disturbance with a suicide attempt. The Blobner phenomenon was positive. The patient had never suffered arthritic, neurological, or vascular involvement and was managing well. She was fairly fit at the time of this survey. When seen again 2 years later she had $\vec{F}$ undergone a right hemicolectomy for abdominal ${ }^{(S)}$ pain thought probably due to Crohn's disease. The? caecal ulcer found in the specimen was $4 \mathrm{~cm}$ in diameter. The base was 'composed of polymorphic oedematous debris, with a deeper fibroblastic reaction infiltration by chronic inflammatory cells of the plasma cell type with a number of eosinophils. $\vec{\circ}$ The appearance did not suggest Crohn's disease. Two adjacent lymph glands examined showedw reactive hyperplasia.'

(3) A third patient (Case 2), a 19-year-old married woman, had had recurrent ulceration either just $\omega_{\sigma}$ anterior to the anus or just inside it. Ulcers wereos associated with pain and responded to steroids asto did her severe mouth ulcers, present since the age of 7. One attack of vulval ulceration had left scarring.? The left shoulder was clinically normal at interview but had been the site of previous arthritis.

CLINICAL MEASUREMENTS

Reduced chest expansion, forward flexion, and lateral flexion of the lumbar spine were found in very few patients (Table 7). No correlations could $\overline{\phi e}-\mathrm{J}$ established with other features of Behcet's disorder

\section{RADIOLOGY}

Radiographs of the sacroiliac joints of 17 patientsi (6 male ( 2 with uveitis), 11 female) were available? No sacroiliitis was found. Abnormal findings indicative of osteoarthrosis were found in the handso of 2 patients and the feet of 2 others.

\section{BLOOD STUDIES}

Estimations of the ESR taken at the time of inter view (when the disease was not necessarily active) showed that the ESR was raised $(>20 \mathrm{~mm}$ in the first hour) in 3 patients but the mean level was onlys $11 \mathrm{~mm}$ (range $2-32 \mathrm{~mm}$ ). No consistent abnorm alities of haemoglobin and white cell count weres observed.

HLA ANTigens (TABles 9, 10)

Twenty-eight patients were HLA typed using microlymphocytotoxicity technique for 21 antigenso (Terasaki et al., 1964). The group consisted of $12 \mathrm{w}$ males and 16 females, the additional members being accounted for by patients seen by the author in the year 1974-75. HLA B5 and HLA B27 were found in increased frequencies in males and in patients of both sexes respectively.

The overall frequency of B5 is not increased in this series but the increased frequency of the antigen in males is comparable with the findings in Japanesळ్ 
Table $9 H L A$ frequencies in Behcet's syndrome

\begin{tabular}{|c|c|c|c|c|c|c|}
\hline & \multirow[b]{2}{*}{$\begin{array}{l}\text { Behcet's } \\
(\text { total }=28)\end{array}$} & \multicolumn{3}{|l|}{ Leeds } & \multicolumn{2}{|l|}{ Japan } \\
\hline & & $\begin{array}{l}\text { Male } \\
(n=12)\end{array}$ & $\begin{array}{l}\text { Female } \\
(n=16)\end{array}$ & $\begin{array}{l}\text { Controls } \\
(n=613)\end{array}$ & $\begin{array}{l}\text { Behcet's } \\
(n=78)\end{array}$ & $\begin{array}{l}\text { Controls } \\
(n=21)\end{array}$ \\
\hline $\begin{array}{l}\text { HLA B5 } \\
\text { HLA B27 }\end{array}$ & $\begin{array}{l}5 \\
(17 \cdot 85 \%) \\
7 \\
(24 \cdot 99 \%)\end{array}$ & $\begin{array}{l}5 \\
(41.65 \%) \\
3 \\
(24.99 \%)\end{array}$ & $\begin{array}{l}0 \\
(0 \%) \\
4 \\
(21 \%)\end{array}$ & $\begin{array}{l}57 \\
(9.39 \%) \\
15 \\
(7.02 \%)\end{array}$ & $\begin{array}{l}15 \\
(71 \cdot 4 \%) \\
\text { NT } \\
\text { NT }\end{array}$ & $\begin{array}{l}24 \\
(30 \cdot 8 \%) \\
\text { NT } \\
\text { NT }\end{array}$ \\
\hline
\end{tabular}

$\mathrm{NT}=$ not tested

Table 10 HLA B27 in Behcet's syndrome

\begin{tabular}{lllll}
\hline Case no. & $M / F$ & Uveitis & Phlebitis & $\begin{array}{l}\text { Gastrointestinal } \\
\text { features }\end{array}$ \\
\hline 4 & F & - & - & - \\
11 & F & - & - & - \\
24 & F & - & + & - \\
25 & F & - & - & - \\
31 & M & + & - & - \\
33 & M & + & - & - \\
Total & & $2 / 6$ & $1 / 6$ & $0 / 6$ \\
\hline
\end{tabular}

patients with Behcet's syndrome (Ohno et al., 1973) (for males $X_{c}^{2}=10.14 ; P=0.0015$ ). There is no significant sex difference in the frequency of B27 in Leeds patients with Behcet's (no figures are available for their Japanese counterparts), the overall frequency being significantly increased compared with controls $\left(X_{c}^{2}=9.68 ; P=0.0019\right)$. This remains significant $(P=0.42)$ even when the original $P$ value is multiplied by 21 to take account of the number of antigens tested (Svejgaard et al., 1974).

\section{IMMUNOGLOBULINS}

IgG was normal in all subjects, but IgA was raised in 8 and IgM in 18. Rheumatoid factor was positive to a titre of 1 in 256 in one subject and the latex fixation was positive in a total of 6 . While indirect immunofluorescence was positive in 11 cases no one system was predominant.

\section{Q - ANALYSIS OF DATA}

Data on the patients were compared with those of relatives and spouses. 32 probands and 21 relatives and no spouses of a total of 22 persons surveyed gave a history of mouth ulceration, but in only 32 probands and 10 relatives was the ulceration evaluated as significant. Genital ulceration was closely linked to mouth ulceration in a way which contrasted with latex fixation testing. This was positive in 31 of the 226 persons in the survey but was only weakly connected with orogenital ulceration both in the total analysis and in the analysis of the patients' file. Erythema nodosum, a positive skin test, acne, and vasculitis emerge from analysis as genuinely and closely, if infrequently, associated with orogenital lesions. Psoriasis and psoriatic arthropathy are found to be associated with backache, sacroiliitis and raised $\operatorname{IgA}$ but dissociated from those features seen in severe Behcet's syndrome.

\section{Discussion}

A population of 5 million resident in the northern part of England (the former County of Yorkshire) comprising both highly industrial towns and sparsely populated rural areas yielded 32 subjects found to have recurrent mouth ulceration and other features.

Genital ulceration was found in $91 \%$, nondestructive arthritis in $47 \%$, skin lesions in $44 \%$, vasculitis in $25 \%$, and iritis in $12 \%$. These figures are similar to those for Behcet's disease in Japan given by Oshima et al. (1963). Strachan and Wigzell (1963) working from a different viewpoint found arthritis in all cases but their frequencies of oral and genital ulceration were somewhat lower and almost identical. Cooper and Penny (1974) and Mason and Barnes (1969) found mouth ulceration in all their patients, with genital ulceration in three-quarters. Even those patients of our series who did not have true genital ulceration reported septic lesions in the area so that there is evidence to support the claim that the diagnosis of Behcet's syndrome should not be considered unless bipolar disease (mouth and genital ulceration) is present. One might keep an open mind about prepubertal children: some of these present with gross mouth ulceration and only later develop genital and other features.

While the series as a whole shows the features enumerated by Behcet and features such as erythema nodosum, vasculitis, and eye lesions are shown by Q-analysis to be closely connected with mouth ulceration, only 3 of our patients would satisfy Behcet's criteria for the triad (mouth ulceration, genital ulceration, and lesions of the anterior chamber of the eye). 21 patients satisfy Mason and Barnes' (1969) definite criteria (without using the family history and cardiovascular lesions). All 
patients except one had two of their four major criteria; this patient had a doubtful history of genital ulceration (recorded as negative) and thrombophlebitis.

Using this last level of certainty the prevalence of known Behcet's syndrome in Yorkshire is 0.064 in 10000 . This is probably representative of the frequency of the condition throughout the United Kingdom and differs markedly from the figures of Aoki et al. (1971). In the remote Hokkaido district off the mainland of Japan they found a prevalence of 1 in 10000 . Of a total of 353 patients, stomatitis was found in 179, genital ulceration in 107, and serious ocular lesions in 284. The incidence of the disease there has apparently risen progressively since 1962 , paralleling a global increase in reported cases: Strachan and Wigzell (1963) listed a total of 45 patients in the world literature from 1932-61 whereas Chajek and Fainaru (1975) gave a total of 724 cases.

Lumbar pain is not a prominent feature of this series and is insignificant beside the other manifestations. Sacroiliitis was not seen in the 17 patients $x$-rayed. Hill (1969) questioned whether sacroiliitis was part of Behcet's syndrome, and Cooper and Penny (1974) mentioned a case of 'clinical sacroiliitis'; the matter is of importance in relating the disease to sacroiliitis in the known seronegative polyarthritides and in turn to HLA B27 or HLA antigens.

While there is a modestly raised incidence of B27 in this series, the level being similar to that found in psoriasis, the frequency of the antigen is much below that found in ankylosing spondylitis and even in Reiter's disease. The British figures confirm the only reported Japanese series in showing an increased incidence of A5 although this rise has been found in males only in the Leeds survey, and its significance awaits further investigation.

The characteristics of the arthritis and arthralgia in this series are consistent with those quoted by Mason and Barnes. Asymmetrical large joint involvement is relatively common; arthralgia may be episodic but rarely migratory although several joints may be involved from time to time. During exacerbations synovial fluid complement is raised and a polymorphonuclear leucocytosis is present (Zizic and Stevens, 1975).

Immunoglobulins $\mathbf{M}$ and $\mathbf{A}$ were raised in this series. Immunoglobulin $\mathbf{A}$ is also raised in psoriasis (and was in our 1 patient who also had psoriasis). Tests for antinuclear factor were consistently negative and although indirect immunofluorescence tests were sometimes positive no definite pattern emerged. Changes documented would suggest that autoimmunity involving the tissues studied is not of great importance in the pathogenesis of Behcet's disease. Immunofluorescence against fetal oral $\frac{0}{\omega}$ mucosa may be more relevant (Lehner, 1967), or these mechanisms may perhaps be brought into action by other as yet unknown factors convergingo on the vasculitis which is commonly observed (France et al., 1951; Enoch et al., 1968).

Behcet himself drew attention to the frequency of $\frac{\alpha}{\alpha}$ sepsis and Blobner (1937) reported on the diagnostic value of sepsis occurring at the site of skin puncture. No false positives were found in the relatives and. spouses of our patients, but a positive skin test had $\vec{\omega}$ no prognostic value. While Sezer (1953) reported a $\stackrel{\omega}{\sigma}$ transmissible virus his work has not so far been repeatable by others and the aetiological importance ${ }_{\omega}$ of infection (viral or bacterial) remains debatable.

The studies of Wright (1965) and Wright and Watkinson, 1965) have shown linkages between bowel disorder such as ulcerative colitis and Crohn's응 disease and ankylosing spondylitis, and between ankylosing spondylitis and psoriasis and Reiter's disease. There have been several reports of ulcerative colitis occurring in the course of Behcet's disease 3 (Bøe et al., 1958; Empey and Hale, 1972) and it is important to differentiate these cases from those in which Behcet's disease itself has resulted in gastro -0 intestinal ulcers or other abnormalities. 3 patient. had gastrointestinal involvement in the present series but one patient had proven Crohn's disease. The expected coincidence of Crohn's disease and Behcet's would be $\mathbf{0} .00576$ per million (based on Evans and Acheson (1965) which gives the Oxford $\stackrel{\mathbb{Q}}{\varrho}$ Cumulative Prevalence as $9 \pm 1.4$ per 100000 ). $\overrightarrow{0}$ Although the likelihood of the two occurring 3 together is remote and the possibility exists that they? are associated, the question whether certain diseases are linked to Behcet's disease can only be resolved by further studies and perhaps by putting all UK? patients on the ARC register. This should allow something more meaningful to be said about the aetiology of Behcet's hinted at by the changes in immunoglobulins, raised incidence of HLA B27 and B5, the vasculitis, and other clinical features.. It is hoped that the family study of which this report is part will also be of value.

It is important to realize these patients are at risk from marital breakdown and self-destruction. Epstein et al. (1970) document 10 cases with severe character disorders and believe that these were of $\omega$ both aetiological and secondary types. None of oure 10 patients with neurotic problems had severe neurological involvement and were in greater danger from their psychiatric problems than from: the physical effects of Behcet's syndrome. Sircus et al. (1957) found a significant number of patients? with depression and anxiety among subjects with 
focal oral ulceration. This is particularly interesting as this common diathesis may be the fertile ground on which Behcet's syndrome grows.

I am greatly indebted to Professor V. Wright, Drs. J. Moll, Guthrie Scott, S. M. Rajah, G. Bevans, D. J. Lintott, I. Haslock, C. Eastmond, Mrs. B. Gordon, Mrs. J. Packter, Mr. Brian Bentley, and Sister M. Binden of the Leeds Teaching Hospitals and University; and to Mr. R. Atkin and Mr. J. Johnson of the Department of Mathematics, University of Essex. This work would not have been possible without their help and that of many others, including the families interviewed.

\section{References}

Aoki, K., Fujioka, K., and Katsumata, H. (1971). Epidemiological studies on Behcet's disease in the Hokkaido district. Japanese Journal of Clinical Ophthalmology, 25, 2239-2243.

Atkin, R. (1974). Mathematical Structure in Human Affairs. Heinemann, London.

Behcet, H. (1937). Uber rezidivierende, aphthose, durch ein virus verursachte Geschwure am Mund am Ange und an den Genitalien. Dermatologische Wochenschrift, 105, 1152-1157.

Blobner, F. (1937). Zur rezidivierenden Hypopyoniritis. Zeitschrift für Augenheilkunde, 91, 129-139.

Bøe, J., Darlgaard, J. B., and Scott, D. (1958). Mucocutaneous-ocular syndrome with intestinal involvement. .4merican Journal of Medicine, 25, 857-867.

Chajek, T., and Fainaru, M. (1975). Behcet's disease. Report of 41 cases and a review of the literature. Medicine, 54, 179-196.

Chamberlain, M. A. (1976). A study of Behcet's disease by $\mathrm{q}$-analysis. International Journal of Man-Machine Studies, 8, 549-565.

Cooper, D. A., and Penny, R. (1974). Behcet's syndrome: clinical, immunological and therapeutic evaluation of 17 patients. Australian and New Zealand Journal of Medicine, 4, 585-596.

Curth, H. O. (1946). Behcet's syndrome, abortive form Archives of Dermatology and Syphilology, 54, 481-484.

Dowling, G. B. (1961). Behcet's disease: discussion on Behcet's disease. Proceedings of the Royal Society of Medicine, 54, 101-104.

Empey, D. W., and Hale, J. E., (1972). Rectal and colonic ulceration in Behcet's disease. Proceedings of the Royal Society of Medicine, 65, 163-164.

Enoch, B. A., Khoo, T. C. L., Castillo-Olivares, J. L., Grainger, R. G., and Henry, L. (1968). Major vascular complications in Behcet's disease. Postgraduate Medica Journal, 44, 453-459.
Epstein, R. S., Cummings, N. A., Sherwood, E. B., and Bergna, D. R. (1970). Psychiatric aspects of Behcet's syndrome. Journal of Psychosomatic Research, 14, 161-172.

Evans, J. G., and Acheson, E. D. (1965). An epidemiological study of ulcerative colitis and regional enteritis in the Oxford area. Gut, 6, 311-324.

France, R., Buchanan, R., Wilson, M. W., and Sheldon, M. B. (1951). Relapsing iritis with recurrent ulcers of the mouth and genitalia-Behcet's syndrome. Medicine, 30, 351-355.

Hill, A. G. S. (1969). Discussion following: Mason, R. M., and Barnes, C. G. Behcet's syndrome with arthritis. Annals of the Rheumatic Diseases, 28, 102.

Lehner, T., (1967). Behcet's syndrome and auto immunity. British Medical Journal, 1, 465-467.

Macrae, I. F., Haslock, D. I., and Wright, V. (1971). Grading of films for sacro-iliitis in population studies. Annals of the Rheumatic Diseases, 30, 58-66.

Mason, R. M., and Barnes, C. G. (1969). Behcet's syndrome with arthritis. Annals of the Rheumatic Diseases, 28 , 95-103.

Moll, J. M. H., (1971). A family study of psoriatic arthritis. DM thesis, University of Oxford.

Moll, J. M. H., and Wright, V. (1972). An objective clinical study of chest expansion. Annals of the Rheumatic Diseases, 31, 1-8.

Moll, J. M. H., Liyanage, S. P., and Wright, V. (1972). An objective clinical method to measure lateral spinal flexion. Rheumatology and Physical Medicine, 11, 225-239.

Ohno, S., Aoki, K., Sugiura, S., Nakayama, E., Itakura, K., and Aizawa, M. (1973). HL-A5 and Behcet's disease. Lancet, 2, 1383-1384.

Oshima, Y., Shimizu, T., Yokhari, R., Matsumoto, T., Kano, K., Kamami, T. and Nagaya, H. (1963). Clinical studies on Behcet's syndrome. Annals of the Rheumatic Diseases, 22, 36-45.

Sezer, N. F. (1953). The isolation of a virus as the cause of Behcet's disease. American Journal of Ophthalmology, 36, 301-315.

Sircus, W., Church, R., and Kelleher, J. (1957). Recurrent aphthous ulceration of the mouth. A study of the natural history, aetiology and treatment. Quarterly Journal of Medicine, 26, 235-249.

Strachan, R. W., and Wigzell, F. W. (1963). Polyarthritis in Behcet's multiple symptom complex. Annals of the Rheumatic Diseases, 22, 26-35.

Svejgaard, A., Jersild, C., Staub Nielsen, L., and Bodmer, W. F. (1974). HL-A antigens and disease, statistical and genetic considerations. Tissue Antigens, 4, 95-105.

Terasaki, P. I. and McClelland, J. D. (1964). Microdroplet assay of human serum cytotoxins. Nature, 204, 998-1000.

Wright, V. (1965). Psoriatic arthropathies. Progress in Clinical Rheumatology, pp. 220-228. Churchill, London.

Wright, V., and Watkinson, G. (1965). Sacro-iliitis and ulcerative colitis. British Medical Journal, 2, 675-680.

Zizic, T. M., and Stevens, M. B. (1975). The arthropathy of Behcet's disease. Johns Hopkins Medical Journal, 136, 243-250. 